\title{
Toxocara polymerase chain reaction on ocular fluids in bilateral granulomatous chorioretinitis
}

This article was published in the following Dove Press journal:

International Medical Case Reports Journal

18 May 2015

Number of times this article has been viewed

\author{
Jenny Xue Tian' \\ Stephen O'Hagan² \\ 'Ophthalmology Department, Cairns \\ Base Hospital, Cairns, QLD, Australia; \\ ${ }^{2}$ Ophthalmology, James Cook \\ University, Cairns, QLD, Australia
}

\begin{abstract}
To report a rare case of bilateral granulomatous chorioretinitis complicated by bilateral peripapillary choroidal neovascular membranes. This is the first reported case in Australia where intravitreal injections of anti-vascular endothelial growth factor ranibizumab were used to successfully treat choroidal neovascular membrane caused by granulomatous chorioretinitis. This is also the first reported case in Australia of Toxocara polymerase chain reaction being performed on intraocular fluids.
\end{abstract}

Keywords: granulomatous chorioretinitis, ocular toxocariasis, neovascular membrane, anti-VEGF

\section{Clinical record}

A healthy 14-year-old boy with a history of contact with dogs presented with reduced vision in his right eye. Best-corrected visual acuity (BCVA) on first presentation was $6 / 36$ in the right eye and 6/5 in the left eye. Fundoscopy revealed bilateral granulomatous chorioretinitis. Serological testing was subsequently conducted to identify the underlying cause for the condition and included analysis for toxoplasmosis, Toxocara, syphilis, sarcoidosis, tuberculosis, rheumatoid factor, antinuclear antibody, anti-neutrophil cytoplasmic antibodies, and Lyme disease. Serological Toxocara testing was performed using ELISA (enzyme-linked immunosorbent assay) technique. The results of these tests were all negative. Plain film chest X-ray and high-resolution chest computed tomography were also performed with no pathology identified, specifically demonstrating no lymphadenopathy to suggest sarcoidosis and no signs of pulmonary tuberculosis. The patient re-presented 2 weeks later with a reduction in vision in his left eye (BCVA was 6/12). Fundoscopy at this stage showed bilateral peripapillary subretinal hemorrhages with subretinal hemorrhage extending into the left macula (Figure 1). Optical coherence tomography scan of the left macula showed macular edema secondary to the subretinal hemorrhage (Figure 2). Fluorescein angiography demonstrated bilateral peripapillary choroidal neovascular membranes (CNVM), a rare complication of granulomatous chorioretinitis (Figure 2). The patient received treatment of monthly intravitreal injections of ranibizumab over a period of 3 months in each eye. BCVA in the left eye improved from 6/12 to 6/5 with regression of the CNVM and resolution of sub-macular blood clearly visible on clinical examination and repeated optical coherence tomography. BCVA in the right eye also improved from $6 / 36$ to $6 / 18$ post-treatment. As the clinical findings were highly suspicious of toxocariasis despite negative Toxocara serology we decided to investigate further by obtaining intraocular fluid samples from both the anterior and posterior chambers for Toxocara polymerase chain reaction (PCR). Since
Correspondence: Jenny Xue Tian Ophthalmology Department, Cairns Base Hospital, 165 The Esplanade, Cairns 4870, QLD, Australia

Tel +6I 424274229

Email jenny.tian@uqconnect.edu.au
International Medical Case Reports Journal 2015:8 107-110

107

Dovepress

http://dx.doi.org// 0.2147/IMCRJ.S84/85 (c) (i) (5) 2015 Tian and 0'Hagan. This work is published by Dove Medical Press Limited, and licensed under Creative Commons Attribution - Non Commercial (unported, v3.0) License. The full terms of the license are available at http://creativecommons.org/licenses/by-nc/3.0/. Non-commercial uses of the work are permitted without any further permission how to request permission may be found at: http://www.dovepress.com/permissions.php 


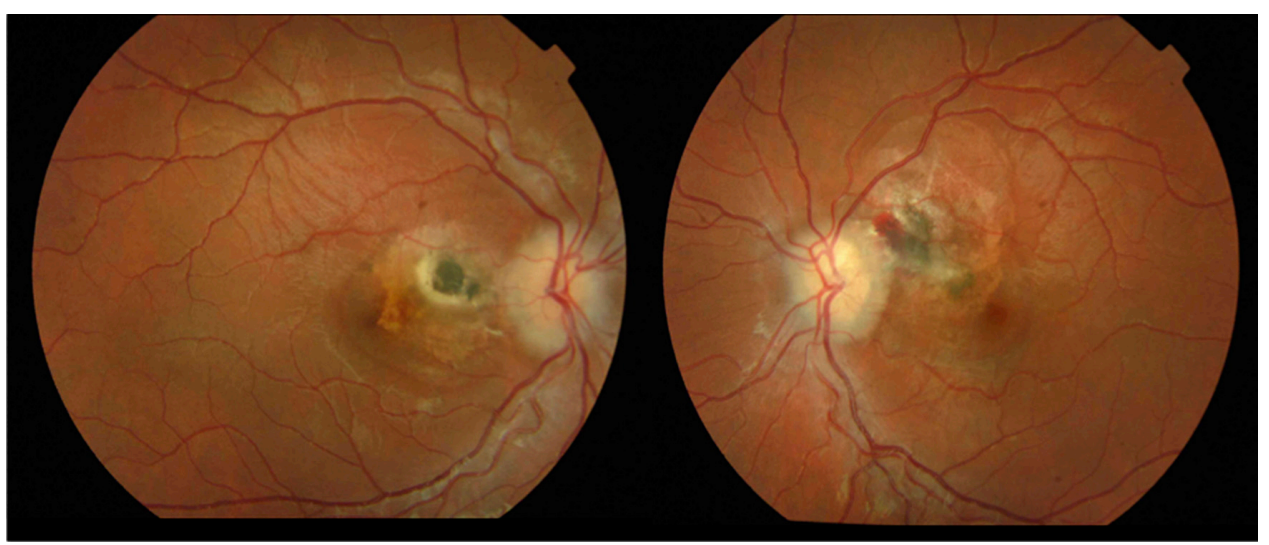

Figure I Fundoscopy showing granulomatous chorioretinitis and peripapillary subretinal haemorrhage in both left eye (right) and right eye (left) with subretinal haemorrhage extending to the left macula (right).

Toxocara PCR was not available in any pathology laboratory in Australia we sent the samples to a research laboratory at the Faculty of Veterinary and Agricultural Science, University of Melbourne, to perform the test. The test returned negative for Toxocara. The patient did not receive anti-helminthic treatment because there was no systemic involvement and no live larva was seen on fundoscopy. ${ }^{1}$ The inflammation in ocular toxocariasis is usually a result from the body's response to the dead worm. ${ }^{1}$

\section{Discussion}

Chorioretinitis is a form of posterior uveitis that affects the choroid and the retina. It can be classified as granulomatous or non-granulomatous on the basis of the predominant pathologic characteristics. Diseases that are known to cause granulomatous inflammation in the eye include tuberculosis, syphilis, sarcoidosis, toxoplasmosis, toxocariasis, and Lyme disease. $^{2}$ In this case the clinical presentation and findings were highly suggestive of toxocariasis despite negative serological and PCR testing.
Toxocariasis is an uncommon infectious parasitic disease caused by the larvae of the nematodes Toxocara canis and Toxocara cati, the common roundworms of dogs and cats respectively. ${ }^{2}$ There have only been 13 reported cases of seropositive patients in Victoria from 2006 to 2014. ${ }^{3}$ People can become infected with Toxocara by eating dirt contaminated with Toxocara eggs, or rarely, from undercooked meat contaminated with Toxocara larvae. ${ }^{4}$ Once inside the human body, the eggs hatch to release the larvae, which penetrate the intestinal wall and enter the circulation to cause visceral and ocular toxocariasis. ${ }^{4}$ Ocular toxocariasis presents as a posterior pole granuloma in $25 \%-50 \%$ of patients. ${ }^{1}$ It causes visual loss usually by direct involvement of macula or optic disk, or by formation of retinal folds or epiretinal membrane, or rarely, by formation of CNVM. ${ }^{1}$ The diagnosis of ocular toxocariasis is often based on the clinical signs and symptoms, which are non-specific, epidemiological data (contact with dogs or cats, consumption of undercooked or raw meats), and laboratory findings. ${ }^{5}$ Retinoblastoma is an important clinical differential of ocular toxocariasis and

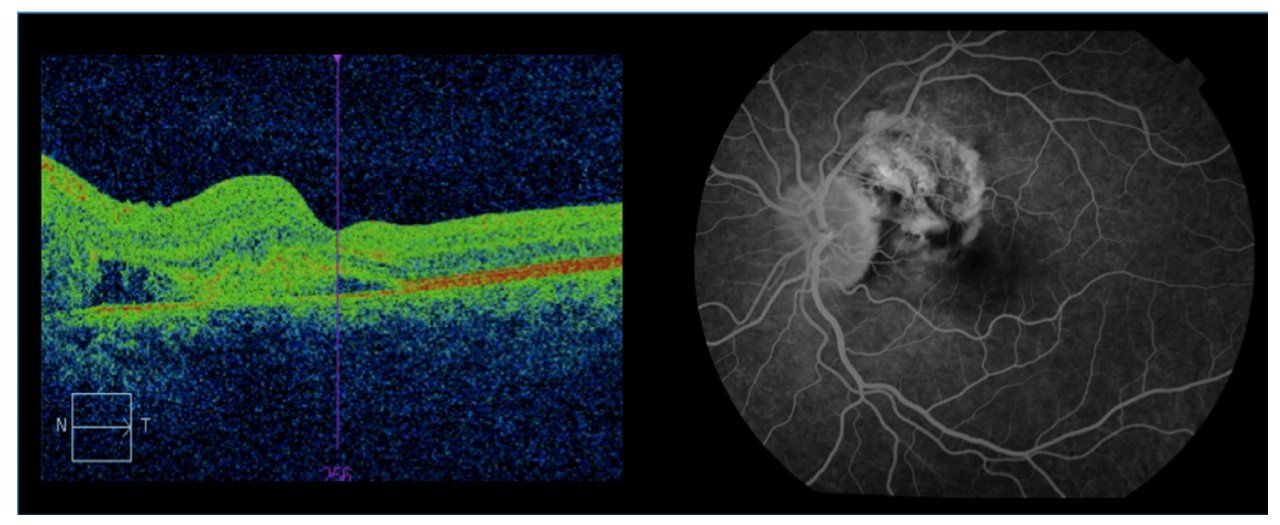

Figure 2 Optical coherence tomography showing left macular edema secondary to subretinal hemorrhage (left); fluorescein angiography of left fundus showing peripapillary choroidal neovascular membrane (right). 
needs to be excluded prior to the diagnosis. ${ }^{6}$ Other causes of granulomatous chorioretinitis that need to be considered include tuberculosis, syphilis, toxoplasmosis, sarcoidosis, and Lyme disease. ${ }^{2}$ Serum ELISA test for Toxocara IgG is helpful for toxocariasis diagnosis but is positive in only $91 \%$ of the cases diagnosed clinically, and a negative result does not rule out the diagnosis. ${ }^{1,6}$ This is because in ocular toxocariasis, due to the low number of infective larvae, serum anti-Toxocara antibodies may be present in very low titers or even undetectable. ${ }^{5}$ Direct detection on biopsy is difficult due to the site of involvement, the size of the larvae, and destruction of organisms with biomicroscopy techniques. In the situation where serological testing for Toxocara is negative, Toxocara PCR can be performed to further aid the diagnosis. In Australia, clinicians do not have access to this test, as currently pathology laboratories do not perform Toxocara PCR analysis. As a result it is possible that the prevalence of toxocariasis in Australia is underestimated. Presently in cases of suspected ocular toxocariasis, Toxocara PCR on human intraocular fluids can only be performed in Australian research laboratories. Although detection of Toxocara spp. DNA is a very sensitive approach it can still be negative in some patients who have very low larval burden, or if the larvae are entrapped or destroyed inside granulomas. ${ }^{7}$

Choroidal neovascular membrane is a rare complication of granulomatous chorioretinitis. ${ }^{8}$ It is believed that chorioretinitis leads to changes in the retinal pigment epithelium and breaks in Bruch's membrane, which may predispose to the development of neovascular membranes. ${ }^{8}$ There have only been a few reported cases around the world where antivascular endothelial growth factor agents have been used to treat CNVM in chorioretinitis, and the results so far have been positive..$^{9,10}$ This is the first case in Australia to report the use of ranibizumab to treat CNVM in granulomatous chorioretinitis and to demonstrate regression of CNVM post-treatment. Ranibizumab is currently TGA (Therapeutic Goods Administration) registered for treatment of neovascular (wet) age-related macular degeneration and visual impairment due to macular edema secondary to diabetes and retinal vein occlusion. ${ }^{11}$ This case highlights the need for further research in the use of ranibizumab for the treatment of visual impairment due to CNVM in granulomatous chorioretinitis.

Our case demonstrates the diagnostic challenge faced by clinicians in the setting of clinically suspected toxocariasis with a negative serological test result. The use of Toxocara PCR testing on intraocular fluids in patients with granulomatous chorioretinitis with a presumptive clinical diagnosis of ocular toxocariasis warrants further investigation. Researching the specificity and sensitivity of Toxocara PCR testing on patients and its clinical accessibility requires more study. This patient developed the rare complication of peripapillary CNVM, which has not been previously reported in the Australian literature and responded well to treatment with intravitreal ranibizumab.

\section{Acknowledgments}

We would like to thank Dr Abdul Jabbar at the Pathobiology Department of Faculty of Veterinary and Agricultural Sciences, University of Melbourne, for assisting us in performing the Toxocara PCR analysis on aqueous and vitreous samples. The subject in this report gave informed consent on all the investigations performed and the subject's anonymity was preserved.

\section{Disclosure}

The authors declare that no financial support was received and there was no competing/conflicting interests in this work.

\section{References}

1. Reviewofophthalmology.com [homepage on the Internet]. Singh A, Cunningham ET, Stewart JM. Detection and Treatment of Ocular Toxocariasis; 2007. Available from: http://www.reviewofophthalmology. com/content/d/retinal_insider/i/1297/c/24974/. Accessed April 13, 2015.

2. Geraint J, Zumla A. The Granulomatous Disorders. UK: Cambridge University Press; 1999.

3. Berger S. Infectious Diseases of Australia [Internet]. Los Angeles: GIDEON Informatics; 2014 [cited November 19, 2014]. Available from: https://books.google.com.au/books?id=Vv59BwAAQBAJ\&pg=PA3\& $\mathrm{dq}=$ Infectious + diseases + of + Australia\&hl $=$ en\&sa $=X \&$ ei $=W B g 7 V d 2 r N$ $6 \mathrm{a} 5 \mathrm{mwWrnoHQAw \& ved}=0 \mathrm{CB} 0 \mathrm{Q} 6 \mathrm{AEwAA} \mathrm{v}=$ onepage $\& \mathrm{q}=$ Infectiou s\%20diseases\%20of\%20Australia\&f=false. Accessed April 25, 2015.

4. Roldan WH, Espinoza YA, Atuncar A, Ortega E, Martinez A, Saravia M Frequency of eosinophilia and risk factors and their association with toxocara infection in schoolchildren during a health survey in the north of Lima, Peru. Rev Inst Med Trop Sao Paulo. 2008;50(5):273-278.

5. Al-Moslih M. Serological Diagnosis of Certain Human, Animal and Plant Diseases. Croatia: Intech; 2012.

6. Jacquier P, Gottstien B, Stingelin Y, Eckert J. Immunodiagnosis of toxocarosis in humans: evaluation of a new enzyme-linked immunosorbent assay kit. J Clin Microbiol. 1991;29(9):1831-1835.

7. Bruschi F. Helminth Infections and their Impact on Global Public Health New York: Springer; 2014.

8. Foster CS, Vitale AT. Diagnosis and Treatment of Uveitis. 2nd ed. New Delhi: Jaypee Brothers Medical Publishers; 2013.

9. Lyall DA, Hutchison BM, Gaskell A, Varikkara M. Intravitreal Ranibizumab in the treatment of choroidal neovascularization secondary to ocular toxocariasis in a 13-year-old boy. Eye (Lond). 2010;24(11):1730-1731.

10. Informahealthcare.com [homepage on the Internet]. Kianersi F, Beni AN, Beni ZN, Ghanbari H. Intravitreal bevacizumab for treatment of choroidal neovascularization secondary to toxoplasmic retinochoroiditis: a case series; 2013. Available from: http://informahealthcare.com/doi/abs/10. 3109/08820538.2013.838278. Accessed April 13, 2015.

11. The Pharmaceutical Benefit Scheme [homepage on the Internet]. Ranibizumab, solution for intravitreal injection, $2.3 \mathrm{mg}$ in $0.23 \mathrm{~mL}$, Lucentis ${ }^{\circledR} ; 2012$. Available from: http://www.pbs.gov.au/info/industry/ listing/elements/pbac-meetings/psd/2012-11/ranibizumab-lucentis. Accessed April 13, 2015. 


\section{Publish your work in this journal}

The International Medical Case Reports Journal is an international, peer-reviewed open-access journal publishing original case reports from all medical specialties. Previously unpublished medical posters are also accepted relating to any area of clinical or preclinical science. Submissions should not normally exceed 2,000 words or

4 published pages including figures, diagrams and references. The manuscript management system is completely online and includes a very quick and fair peer-review system, which is all easy to use. Visit http://www.dovepress.com/testimonials.php to read real quotes from published authors.

Submit your manuscript here: http://www.dovepress.com/international-medical-case-reports-journal-journal 